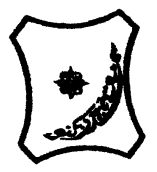

Bayero Journal of Pure and Applied Sciences, 11(1): 33 - 39

ISSN $2006-6996$

\title{
EVALUATION OF INDIGENOUS RHIZOBIAL ISOLATES IN SEARCH FOR CANDIDATE STRAIN FOR COMMERCIAL PRODUCTION
}

\author{
Aliyu, ${ }^{1 *}$ I.A., Yusuf, ${ }^{1}$ A.A. and Atta, ${ }^{2}$ A. \\ ${ }^{1}$ Department of Soil Science, Faculty of Agriculture/Institute for Agricultural Research, Ahmadu \\ Bello University P.M.B. 1044, Zaria, Nigeria \\ ${ }^{2}$ National Research Institute for Chemical Technology, Zaria Nigeria \\ *Corresponding Author: ibrabuba@gmail.com, iaaliyu@abu.edu.ng; 0805778 4973, 08139117279
}

\section{ABSTRACT}

High cost of Nitrogen (N) fertilizer coupled with its potential deleterious effect on soil properties necessitates the need for alternative sources. Grain legumes in association with rhizobia contribute immensely in nitrogen accrual to agricultural system by fixing $N$ from the atmosphere. An essential component for increasing the use of grain legumes is research leading to the selection and development of effective strains of rhizobia for commercial use. Fifty (50) indigenous rhizobial strains were collected from the gene bank of Soil Microbiology Laboratory at Institute for Agricultural research (IAR), Ahmadu Bello Zaria and screened for their symbiotic effectiveness. The test crop was Soybean variety TGX $1448-2 E$ grown in $3 \mathrm{~kg}$ pot in screenhouse at the same Institute. Treatments included the 50 different strains, 3 commercial strains and 2 controls $(-N$ and $+N$ controls). Nodulation and dry biomass production were used to assess the performances of the inoculants vis-à-vis the commercial ones and the controls. The result showed that $70 \%$ of the strains outperformed the controls and commercial strains in terms of nodule number, $74 \%$ nodule dry weight while $18 \%$ recorded higher dry matter yield over control. However only $14 \%, 26 \%$ and $1 \%$ recorded significantly higher nodule number, nodule dry weight and dry matter yield respectively over the controls and commercial strains. Outstanding strains include SAMFIX036, SAMFIX074, SAMFIX113, SAMFIX306, SAMFIX369, SAMFIX381 and SAMFIX221. Hence, further characterization and field evaluation across multiple locations need to be carried out on these strains, as they may be suitable candidates for commercial production.

Keywords: Candidate strain, Dry-biomass, Nodulation, Rhizobia isolates, SAMFIX.

\section{INTRODUCTION}

Sustainable agriculture depends on soil fertility and health. But low yield are often experienced due to continuous cropping without replenishment. One major way of replenishing soil fertility is through application of mineral fertilizers. However, because of the cost involved, many farmers cannot afford it thereby applying below recommendation. Consequently, research efforts have been directed towards integrated nutrient management (INM), in which leguminous crops play a key role (Mafongoya et al., 2007) due to their nitrogen fixing ability. Biological Nitrogen Fixation (BNF) is a key source of $N$ for farmers who use little or no fertilizer, especially for legumes such as soybean (Smaling et al., 2008). Based on the several other studies, it has been widely shown that up to $80 \%$ of the aboveground $\mathrm{N}$ accumulation in soybean is due to BNF (Hungria et al., 2006). Depending on the legume variety, net soil $\mathrm{N}$ accrual from the incorporation of grain legume residue can be as much as $140 \mathrm{~kg} \mathrm{~N}^{-1}$ if only seeds are harvested (Giller, 2001). This is by far more than $50 \mathrm{~kg}$ nutrient ha ${ }^{-1}$ recommendation of the summit meeting of African head of states held in Abuja, Nigeria in order to improve agricultural productivity and hence food security. Biological Nitrogen fixation has therefore been used in farming systems to cut down on fertilizer expenses (Shamseldin, 2007). Grain legumes fix atmospheric nitrogen by working symbiotically with special bacteria, rhizobia, which live in their root nodules. The fixed nitrogen is then used by the grain legumes or carried-over in the soil for the next year's crop. Therefore, the successful use of grain legumes in cropping system depends upon appropriate formation of effective symbioses with these bacteria. An essential component for increasing the use of grain legumes is the appropriate research leading to the selection of elite strains of rhizobia. 


\section{Special Conference Edition, November, 2018}

Evidence from various strain screening programs indicates that yields of several grain legumes can be improved substantially by inoculation with compatible rhizobia. However, research to select the best strains is often piecemeal, lacking rigorous screening of large numbers of isolates. The aim of this research therefore, is to screen large number of isolates in searching for candidate strain(s) for commercial production.

\section{MATERIAL AND METHODS}

Bio-prospection
The screening exercise starts with bioprospection in which nodules of soybean were sampled from three agro-ecological (Southern Guinea Savanna (SGS) Northern Guinea Savanna (NGS) and Sudan Savanna (SS)) zones of Nigeria. Sampling sites were spread in various geographical locations (Table 1). The sampled nodules were stored in a plastic vials containing cotton wools underneath which containing silica gel. The vials were kept in the lab at room temperature until isolation. The isolates were kept in the gene bank at $-80^{\circ} \mathrm{C}$.

Table 1: Inoculant strains and description of the sampling sites (2016).

\begin{tabular}{|c|c|c|c|c|c|}
\hline S/N & Inoculant & Ecological zone & Location & Longitude & Latitude \\
\hline 1 & SAMFIX097 & SS & Warawa & E008.690167 & N11.9729 \\
\hline 2 & SAMFIX224 & SS & Garko & E008.812417 & N11.67942 \\
\hline 3 & SAMFIX205 & SGS & Kachia & E007.973617 & N9.843383 \\
\hline 4 & SAMFIX339 & SS & Dawakin kudu & E008.719967 & N11.83513 \\
\hline 5 & SAMFIX245 & SS & Garko & E008.93825 & N11.59038 \\
\hline 6 & SAMFIX302 & NGS & Tudun Wada & E008.3566 & $\mathrm{N} 11.24617$ \\
\hline 7 & SAMFIX256 & SS & Garko & E008.92625 & N11.58275 \\
\hline 8 & SAMFIX287 & SS & Minjibir & E008.667133 & N12.14323 \\
\hline 9 & SAMFIX275 & SGS & Kachia & E007.969133 & N9.8112 \\
\hline 10 & SAMFIX347 & SS & Albasu & E008.983 & N11.66993 \\
\hline 11 & SAMFIX326 & SS & Dawakin kudu & E008.58725 & N11.85205 \\
\hline 12 & SAMFIX315 & SS & Wudil & E008.9215 & N11.6556 \\
\hline 13 & SAMFIX163 & SS & Albasu & E009.19255 & N11.676 \\
\hline 14 & SAMFIX154 & SS & Albasu & E009.132783 & N11.67317 \\
\hline 15 & SAMFIX306 & NGS & Giwa & E007.388283 & N11.34945 \\
\hline 16 & SAMFIX129 & SS & Bichi & E008245217 & N12.22797 \\
\hline 17 & SAMFIX135 & SS & Bichi & E008.29685 & N12.20575 \\
\hline 18 & SAMFIX174 & SS & Dawakin kudu & E008.58725 & N11.85205 \\
\hline 19 & SAMFIX036 & NGS & Soba & E007.919883 & N11.02645 \\
\hline 20 & SAMFIX043 & NGS & Soba & E007.92 & N11.02662 \\
\hline 21 & SAMFIX003 & NGS & Giwa & E007.3817 & N11.27788 \\
\hline 22 & SAMFIX080 & NGS & Igabi & E007.643 & N10.94175 \\
\hline 23 & SAMFIX113 & SS & Wudil & E008.9215 & N11.6556 \\
\hline 24 & SAMFIX074 & NGS & Igabi & E007.687117 & N10.7816 \\
\hline 25 & SAMFIX221 & SS & Garko & E008.812417 & N11.67942 \\
\hline 26 & SAMFIX359 & NGS & Kubau & N10. 37708 & E 008.40692 \\
\hline 27 & SAMFIX353 & SS & Warawa & N11.88573 & E 008.74815 \\
\hline 28 & SAMFIX397 & SS & Warawa & N11.88573 & E 008.74815 \\
\hline 29 & SAMFIX355 & SS & Warawa & N11.86805 & E 008.74295 \\
\hline 30 & SAMFIX399 & SS & Warawa & N11.86805 & E 008.74295 \\
\hline 31 & SAMFIX365 & SS & Bunkure & N11.69337 & E 008.56103 \\
\hline 32 & SAMFIX406 & SS & Bunkure & N11.69337 & E 008.56103 \\
\hline 33 & SAMFIX366 & NGS & Giwa & N11.24892 & E 007.25378 \\
\hline 34 & SAMFIX407 & NGS & Giwa & N11.24892 & E 007.25378 \\
\hline 35 & SAMFIX368 & NGS & Giwa & N11.25678 & E 007.25215 \\
\hline 36 & SAMFIX409 & NGS & Giwa & N11.25678 & E 007.25215 \\
\hline 37 & SAMFIX369 & NGS & Giwa & $\mathrm{N} 11.26011$ & E 007.27394 \\
\hline 38 & SAMFIX371 & SS & Shanono & N12.03446 & E 008.00910 \\
\hline 39 & SAMFIX373 & SS & Shanono & N12.04047 & E 008.02526 \\
\hline 40 & SAMFIX375 & SS & Shanono & N12.04438 & E 008.02065 \\
\hline 41 & SAMFIX414 & SS & Shanono & N12.04438 & E 008.02065 \\
\hline 42 & SAMFIX376 & SS & Shanono & N12.03934 & E 008.02147 \\
\hline 43 & SAMFIX379 & SS & Shanono & $\mathrm{N} 12.04260$ & E 008.02147 \\
\hline 44 & SAMFIX381 & NGS & Tudun Wada & N11.28076 & E008.42105 \\
\hline 45 & SAMFIX382 & NGS & Tudun Wada & N11.33968 & E 008.40641 \\
\hline 46 & SAMFIX383 & NGS & Tudun Wada & N11.28018 & E008.42166 \\
\hline 47 & SAMFIX418 & NGS & Tudun Wada & N11.33968 & E 008.40641 \\
\hline 48 & SAMFIX422 & NGS & Tudun Wada & N11.31669 & E008.43719 \\
\hline 49 & SAMFIX388 & NGS & Tudun Wada & N11.33701 & E 00.40556 \\
\hline 50 & SAMFIX392 & NGS & Igabi & N10.80128 & E 007.67453 \\
\hline
\end{tabular}

SGS= Southern Guinea Savanna; NGS = Northern Guinea Savanna; SGS= Southern Guinea Savanna; and SS= Sudan Savanna 
Isolation, growing and multiplication of rhizobial strains

Firstly, a yeast mannitol ager (YMA) was prepared as outlined by Woomer et al. (2010). A nodule from each vial was selected and surface sterilized to remove all the surface microorganisms (Woomer et al., 2010). Each of the nodules was then transferred into fresh and sterilized petri dish and crushed open using flame sterilized spatula thereby making the rhizobia to break loose into solution in the petri dish. A flame sterilized wire loop was used to scoop a loopful of rhizobia solution and then streaked on the already prepared YMA plate. Finally the plates were incubated at room temperature inside an incubator. Plates were observed every day to see if there were growths. Plate for each isolate was observed and colonies were confirmed. The grown colonies were then stored in a vial of YMA at $4^{\circ} \mathrm{C}$ for further use. This makes the bank of the isolates, which contains as much as 600 strains isolated from different grain legumes including soybean, groundnut, cowpea and Bambara groundnut. This screening study focused only on soybean isolates as the aim was only to produce soybean inoculums. Hence, 50 strains isolated from soybean nodules were randomly selected from the bank (Table 1) and used for the screening exercise.

The rhizobial strains were grown and multiplied in a yeast mannitol broth (YMB) as outlined by Woomer et al. (2010). Each of the selected strain was then inoculated into respective 250 $\mathrm{ml}$ Erlenmeyer flask containing YMB. The inoculated $Y M B$ for each isolate was incubated in a rotatory shaker for at least a week for the isolates to mature.

\section{Screenhouse experiment}

The experiment was conducted in a screenhouse at the Department of Soil Science, Institute for Agricultural Research (IAR), Ahmadu Bello University Zaria (latitude $11^{\circ} 12^{\prime \prime} \mathrm{N}$ and longitude $07^{\circ} 37^{\prime \prime} \mathrm{E}$ on the elevation of $638 \mathrm{~m}$ ) Nigeria. The soil was taken from IAR's field at $0-15 \mathrm{~cm}$ depths, bulked, airdried, sieved through $4 \mathrm{~mm}$ mesh and weighed into plastic pots (3 liters). Three kilograms of soil were put in the plastic pots. Optimum amount of nutrients solutions were applied into the soil and left to equilibrate for 24 hours. This was then followed by planting a soybean seeds at rate of 3 seeds/pot and thinned down to 1 plant / pot a week after germination. The treatments included 50 isolates from the gene bank (Table 1), 2 controls ( $\mathrm{N}$ (control) and $+\mathrm{N}$ (Nitrogen)) and 3 reference strains (GraphEx, Legumefix and Nodulaid) replicated 3 times and laid in a completely randomized design (CRD). The experiment was managed by irrigating the plants every day as required. At two weeks after planting (WAP), the seedlings were inoculated at the root zone $(5 \mathrm{ml}$ of each inoculant was injected with a syringe at around rhizosphere).

\section{Harvesting}

Plants were harvested at eight weeks after planting. The plants were carefully removed from the pots, the shoots were cut at the soil surface level using sharp knife. The shoots were taken to the laboratory and oven dried at $60^{\circ} \mathrm{C}$ to constant weight for dry weight measurement. The roots were carefully washed in water making sure that the nodules were not detached from the roots. The roots were then taken to the lab where the nodules were carefully removed. Nodule number was determined as well as their dry weight. The roots were then oven dried at $60 \mathrm{C}$ to determine their dry weights.

\section{Statistical analysis}

All data collected were subjected to analysis of variance (ANOVA) Using SAS software 9.4. Differences between means were separated using Duncan multiple range test (DMRT). Correlation analyses were used to compare relationships between variables.

\section{RESULTS}

The figures presented showed comparison between the commercial inoculants, tested strains and the control. Here, the control is used as the benchmark for the comparison. It is therefore considered that those strains that surpassed control statistically are candidate strains for commercial production.

Analysis of nodule number following inoculation showed that there was highly significant $(P<0.001)$ difference among the isolates, commercial inoculants and the controls (Figs 1a to 1d). Each figure compares ten different strains alongside controls and standard commercial inoculants.

From Fig $1 \mathrm{a}$, it showed that $70 \%$ of the strains have higher nodule number than the control. However, only 30\% were found to be statistically $(P<0.01)$ higher than the control. These were notably SAMFIX 036, SAMFIX 074 and SAMFIX 113. Also, Fig. 1b showed that $70 \%$ of the tested strains were higher than control but only SAMFIX $2211 \mathrm{~d}$ showed that $70 \%$ and $80 \%$ of the inoculants respectively had higher nodule number. SAMFIX 306 (Fig. 1c), SAMFIX 369 and SAMFIX 381 (Fig. 1d) were found to be significantly $(P<0.01)$ higher than control. While $60 \%$ of the Fig. 1e recorded higher nodule number, none of them were statistically different from the control. Generally, $70 \%$ of the strains tested recorded higher nodule number compared to the control. However, only $14 \%$ were found to be statistically higher than the control. 


\section{Special Conference Edition, November, 2018}

Analysis of nodule dry weight has shown that $74 \%$ of the tested strains recorded higher nodule number than control (Table 2). However when statistically analyzed, only $26 \%$ recorded significantly $(P<0.01)$ higher nodule dry weight.

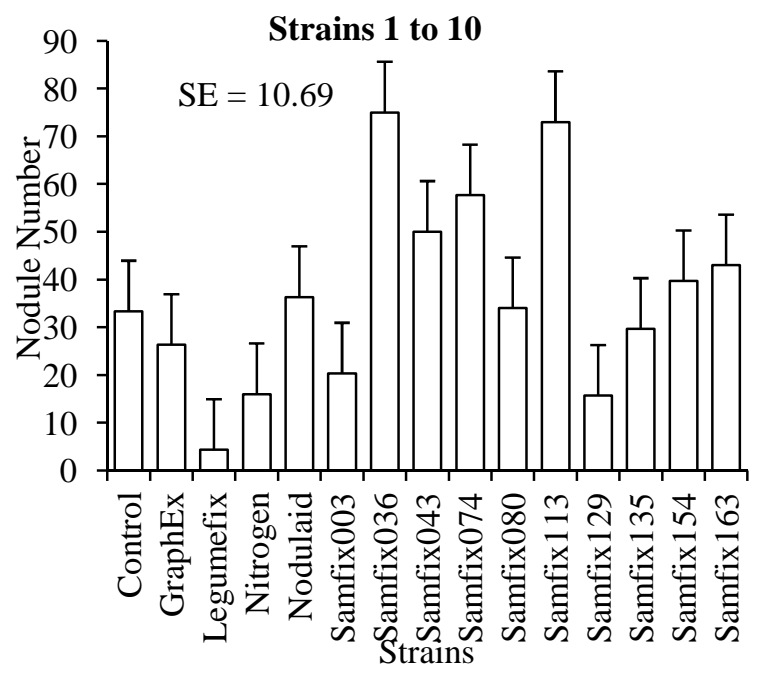

(a)

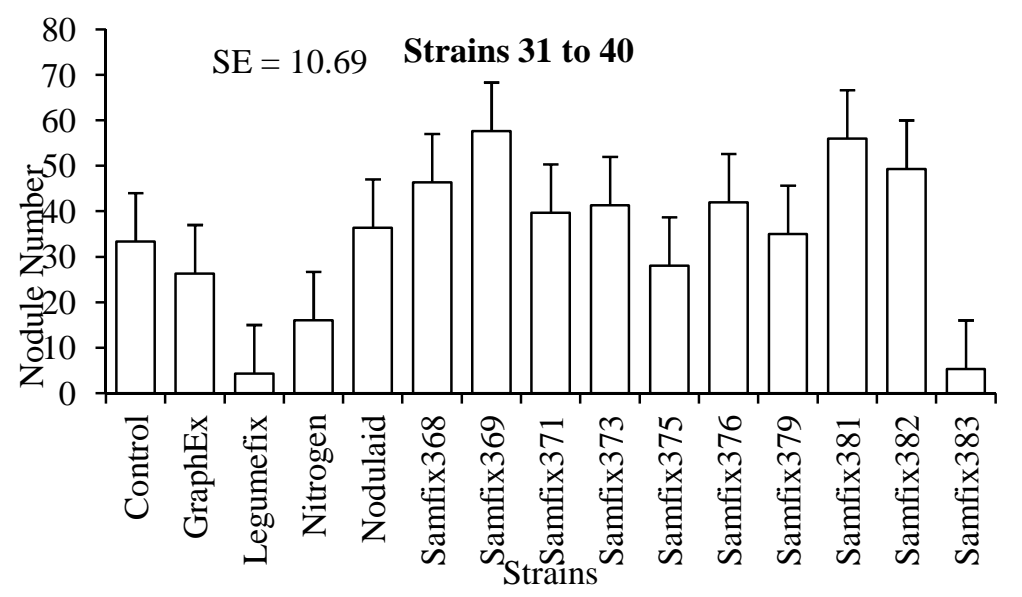

Analysis of the dry matter yield has shown that only $18 \%$ of the tested strains recorded higher dry matter yield (Table 2). However, only SAMFIX 221 recorded a significantly $(P<0.05)$ higher dry matter yield compared to control.

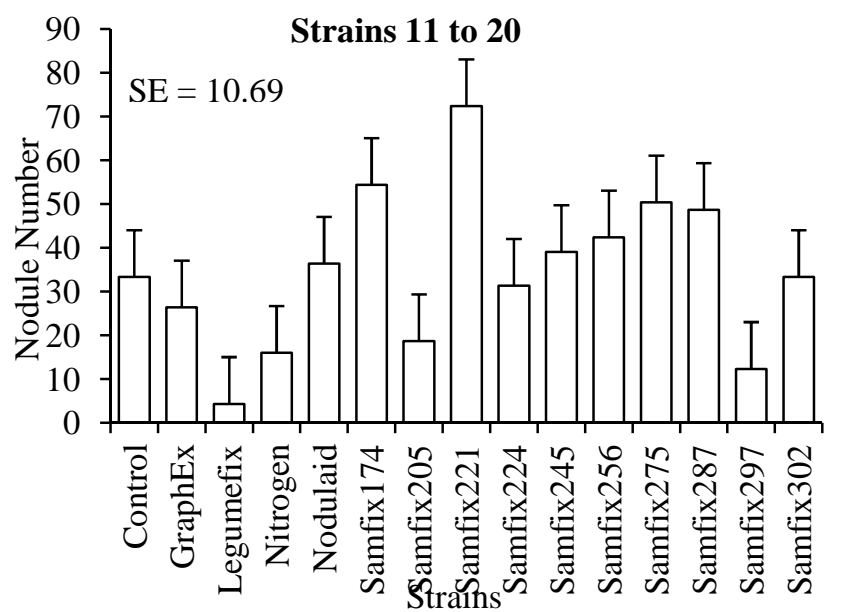

(b)

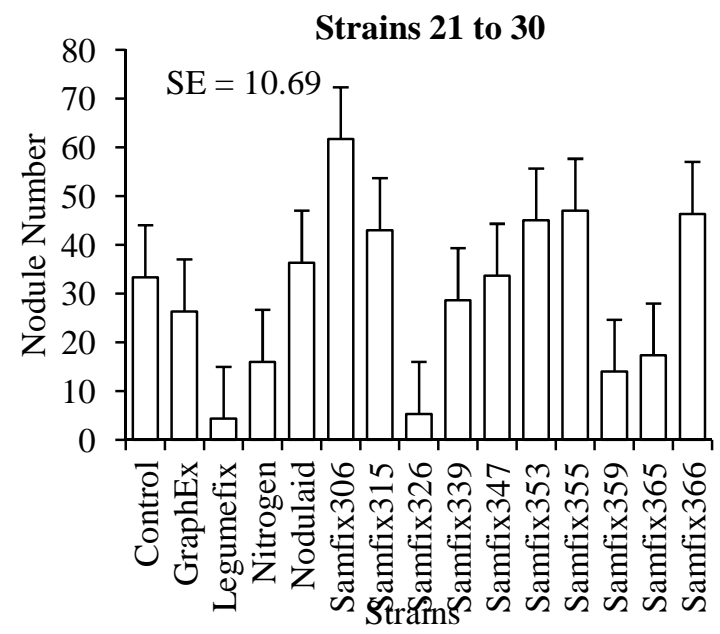

(c)

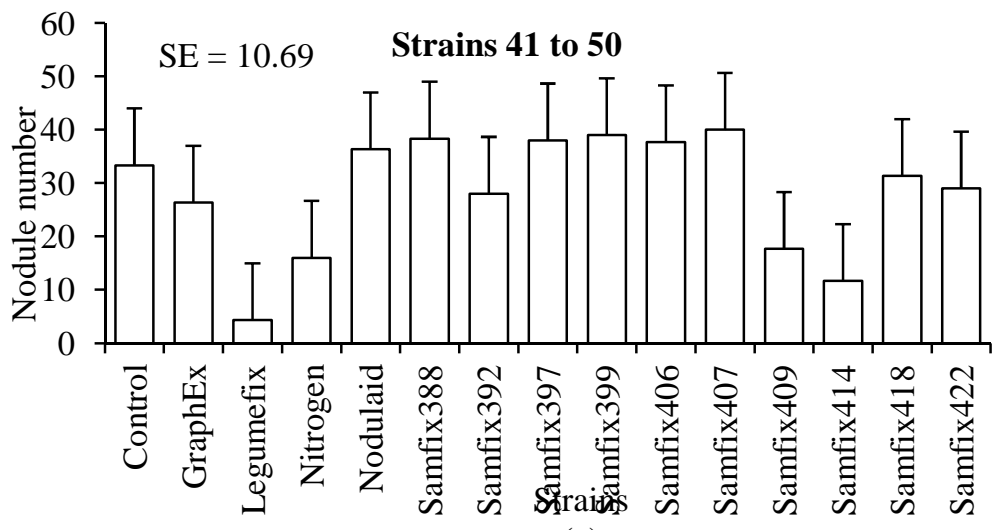

(e)

Fig 1a-e: Comparison of the isolated strains ${ }^{(\mathrm{d})}$ alongside control and reference strains in terms of nodule number 
Table 2: Mean nodule dry weight and dry matter yield of soybean as affected by the isolated

\begin{tabular}{clcccccc}
\hline S/N & Treatment & $\begin{array}{c}\text { Nodule Dry } \\
\text { Weight }(\mathbf{m g})\end{array}$ & $\begin{array}{c}\text { Dry Matter } \\
\text { Yield }(\mathbf{g})\end{array}$ & S/N & Treatment & $\begin{array}{c}\text { Nodule Dry } \\
\text { Weight }(\mathbf{m g})\end{array}$ & $\begin{array}{c}\text { Dry Matter } \\
\text { Yield (g) }\end{array}$ \\
\hline 1 & Control & 110.00 & 8.18 & 29 & SAMFIX339 & 209.33 & 7.73 \\
2 & GraphEX & 97.00 & 5.13 & 30 & SAMFIX347 & 217.67 & 8.51 \\
3 & Legumefix & 8.67 & 5.20 & 31 & SAMFIX353 & 233.33 & 7.54 \\
4 & Nitrogen & 39.33 & 7.24 & 32 & SAMFIX355 & 300.33 & 8.04 \\
5 & Nodulaid & 91.00 & 6.61 & 33 & SAMFIX359 & 65.33 & 6.56 \\
6 & SAMFIX003 & 87.00 & 6.44 & 34 & SAMFIX365 & 72.33 & 6.61 \\
7 & SAMFIX036 & 309.33 & 8.08 & 35 & SAMFIX366 & 301.00 & 9.90 \\
8 & SAMFIX043 & 265.00 & 7.61 & 36 & SAMFIX368 & 209.00 & 6.80 \\
9 & SAMFIX074 & 188.33 & 7.46 & 37 & SAMFIX369 & 138.33 & 6.53 \\
10 & SAMFIX080 & 172.00 & 8.65 & 38 & SAMFIX371 & 134.33 & 7.76 \\
11 & SAMFIX113 & 301.00 & 7.92 & 39 & SAMFIX373 & 137.00 & 6.38 \\
12 & SAMFIX129 & 43.67 & 6.32 & 40 & SAMFIX375 & 254.67 & 8.66 \\
13 & SAMFIX135 & 149.00 & 7.45 & 41 & SAMFIX376 & 91.98 & 5.58 \\
14 & SAMFIX154 & 271.33 & 7.10 & 42 & SAMFIX379 & 125.36 & 6.58 \\
15 & SAMFIX163 & 167.67 & 7.81 & 43 & SAMFIX381 & 221.00 & 8.71 \\
16 & SAMFIX174 & 170.67 & 7.77 & 44 & SAMFIX382 & 188.67 & 8.97 \\
17 & SAMFIX205 & 55.00 & 6.22 & 45 & SAMFIX383 & 13.33 & 4.97 \\
18 & SAMFIX221 & 383.67 & 10.33 & 46 & SAMFIX388 & 116.33 & 6.60 \\
19 & SAMFIX224 & 163.00 & 6.98 & 47 & SAMFIX392 & 105.33 & 6.25 \\
20 & SAMFIX245 & 136.00 & 7.67 & 48 & SAMFIX397 & 169.00 & 7.01 \\
21 & SAMFIX256 & 118.67 & 5.66 & 49 & SAMFIX399 & 240.67 & 8.53 \\
22 & SAMFIX275 & 249.00 & 8.22 & 50 & SAMFIX406 & 216.33 & 6.68 \\
23 & SAMFIX287 & 223.00 & 7.44 & 51 & SAMFIX407 & 236.33 & 7.61 \\
24 & SAMFIX297 & 51.00 & 6.81 & 52 & SAMFIX409 & 81.00 & 7.23 \\
25 & SAMFIX302 & 105.00 & 5.69 & 53 & SAMFIX414 & 27.67 & 4.14 \\
26 & SAMFIX306 & 199.67 & 7.68 & 54 & SAMFIX418 & 159.67 & 5.67 \\
27 & SAMFIX315 & 259.00 & 7.82 & 55 & SAMFIX422 & 169.00 & 6.65 \\
28 & SAMFIX326 & 7.67 & 4.44 & & & & \\
& & SE $=56.78$ & SE $=0.97$ & & & SE 56.78 & SE = 0.97 \\
\hline
\end{tabular}

strains, controls and reference strains.

The Pearson correlation matrix was carried out to see if there were relationships between the measured variables (Table 3). It was found that nodule number was significantly $(P<0.0001)$ correlated with both the nodule dry weight and dry matter yield.

Table 3: Correlation matrix between nodule number dry weight and dry matter yield.

\begin{tabular}{lccccc}
\hline & $\begin{array}{c}\text { Nodule } \\
\text { number }\end{array}$ & $\begin{array}{c}\text { Nodule Dry } \\
\text { Weight }\end{array}$ & $\begin{array}{c}\text { Shoot Dry } \\
\text { Weight }\end{array}$ & $\begin{array}{c}\text { Root Dry } \\
\text { Weight }\end{array}$ & $\begin{array}{c}\text { Dry Matter } \\
\text { Yield }\end{array}$ \\
\hline Nodule number & - & & & & \\
Nodule Dry Weight & $0.589^{* * *}$ & - & & & \\
Shoot Dry Weight & $0.336^{* * *}$ & $0.773^{* * *}$ & - & & \\
Root Dry Weight & $0.072^{\text {Ns }}$ & $0.316^{* * *}$ & $0.519^{* * *}$ & - & \\
Dry Matter Yield & $0.291^{* * *}$ & $0.716^{* * *}$ & $0.962^{* * *}$ & $0.733^{* * *}$ & - \\
\hline$* * *$ & $P<0.001 ;$ NS $=$ Not Significant & & & &
\end{tabular}

\section{DISCUSSION}

Effectiveness of isolated strains of rhizobia is usually improved through screening of large number of rhizobial inoculants that have the capacity of acclimatizing themselves to specific soil environment to which they are applied. The result of the screening exercise showed that there were variations in nodulation and dry matter yield assessment. Some of the strains exhibited a higher nodulation and dry matter yield compared to the controls, reference strains and other isolates. 
This shows that the nodulation potential of these strains and their competitive ability vary based on their origin i.e. where they were isolated from, the characteristics of the soils they were isolated from etc. This simply implies that some isolated strains are more efficient than the others in terms of symbiotic effectiveness. Rhizobia strains of different origin vary in their symbiotic efficiency (Zaman-Allah, 2007). Also, Fening and Danso (2002) reported that Bradyrhizobia number and effectiveness vary considerably among locations.

Among the isolated strains tested, SAMFIX 036, SAMFIX 074, SAMFIX 113, SAMFIX 306, SAMFIX 369, SAMFIX 381 and SAMFIX 221 were found to be outstanding. They demonstrated higher symbiotic efficiency than the other isolates, reference strains and controls. They can therefore be recommended as candidate strain for commercial production. Isolates of indigenous rhizobium have been demonstrated to produce successful results (Sessitsch et al., 2002). A good example is Rhizobium tropici PRF81, isolated from Brazilian soil and recommended as a commercial inoculant for common bean (Phaseolus vulgaris L.) in Brazil since 1998 (Hungria and Vargas, 2000). Similarly, Drevon et al. (2001) isolated 49 indigenous rhizobia from Morocco and Tunisia and found that they are at least as efficient as commercial inoculant CIAT899 in symbiosis with local cultivar. The reference strains and some other isolates failed to improve the nodulation and dry matter of soybean. It is possible that rhizobial cells in these strains did not survive the storage process and therefore were in poor

\section{REFERENCES}

Catroux, G., Hartmann, A. and Revellin, C. (2001). Trends in rhizobial inoculants production and use. Plant and Soil, 230: $21-30$.

Drevon, J.J., Abdelly, C., Armarger, N., Aouani, E.A. Aurag, J., Gherbi, H., Jebara, Y., Lluch, C., Payre, H., Schump, O., Soussi, M., B. Sifi. and M. Trabelsi. (2001). An interdisciplinary research strategy to improve symbiotic nitrogen fixation and yield of common bean (Phaseolus vulgaris) in salinized areas of the Mediterranean basin. Journal of Biotechnology, 91: 257 268.

Fening, J.O. and S.K.A. Danso, (2002). Variation in symbiotic effectiveness of cowpea Bradyrhizobia indigenous to Ghanaian soils. Applied Soil Ecology, $21: 23-9$.

Giller, K.E. (2001). Nitrogen fixation in tropical condition at the time of their application. The success of commercial inoculants is dependent on the number of viable bacteria available to participate in the infection process at the point of use (Catroux et al., 2001). Hiltbold et al. (1980) reported that nodulation of soybean was directly related to number of rhizobia with no nodulation by the product supplying $<10^{3}$ rhizobia/seed and abundant by about $10^{5}$ to $10^{6}$ rhizobia/seed.

The analysis of the correlation coefficient matrix clearly revealed significant positive relationship between nodule number and dry matter yield $\left(r=0.291^{* * *}\right)$ and the nodule dry weight with dry matter yield $\left(r=0.716^{* * *}\right)$. This implies that nodule number and nodule dry weight can be used as criteria for prediction of inoculation response as opined by Nambiar (1985) and Wange (1989).

\section{CONCLUSION}

The study on evaluation of indigenous rhizobial isolates has shown that some of the indigenous rhizobial strains have higher symbiotic efficiency than others, which resulted in higher nodulation and dry biomass yield. Certain strains outperformed the commercial strains and controls statistically and therefore were recommended as best candidates for commercial production. However, further characterization and field evaluation across multiple locations are necessary to authenticate their veracity as commercial inoculants.

\section{Acknowledgement}

The authors express their sincere gratitude to National Research Institute for Chemical Technology (NARICT) for sponsoring this work.

cropping system. 2nd edition. CABI publishing, Wallingford, UK. $423 \mathrm{pp}$.

Hiltbold, A.E., Thurlow, D.L. and Skipper, H.D. (1980). Evaluation of commercial soybean inoculants by various techniques. Agronomy Journal, 72:675 $-681$.

Hungria, M. and Vargas, M. A. T. (2000). Environmental factors affecting $\mathrm{N}_{2}$ fixation in grain legumes in the tropics, with an emphasis on Brazil. Field Crops Research, 65:151-164.

Hungria, M., Franchini, J.C., Campo, R.J., Crispino, C.C., Moraes, J.Z., Sibaldelli, R.N.R., Mends, I.C., and Arihara, J. (2006). Nitrogen nutrition of soybean in Brazil: contributions of biological N2fixation and $\mathrm{N}$ fertilizer to grain yield. Canadian Journal of Plant Science, 86:927 - 939. 
Mafongoya, P.L., Bationo, A., Kihara, J., and Waswa, B.S. (2007). Appropriate technologies to replenish soil fertility in Africa, in: Bationo A., Waswa B.S., Kihara J., Kimetu J. (Eds.), Advances in integrated soil fertility management in sub Saharan Africa: challenges and opportunities, Springer, Netherlands, pp. 29 - 44.

Nambiar, P.T.C. (1985). Response of groundnut (Arachis hypogaea L.) to rhizobium inoculation in field: problems and prospects. MIRCEN Journal, 1:293 309.

Sessitsch, A., Howieson, J.G., Perret, X., Antoun, $\mathrm{H}$. and Martinez-Romero, $\mathrm{E}$. (2002). Advances in Rhizobium research. Critical Reviews in Plant Sciences, 21: 323-378.

Shamseldin, A. (2007). Use of DNA marker to select well-adapted Phaseolussymbionts strain under acidic conditions and high temperature. Biotechnology Letter, 29: 37- 44.

Smaling, E., Roscoe, R., Lesschen J., Bouwman A. and Comunello E. (2008). From forest to waste: Assessment of the Brazilian soybean chain, using nitrogen as a marker. Agriculture, Ecosystems and Environment, 128:185197.

Wange, S.S. (1989). Response of groundnut to inoculation with rhizobium strains isolated from wild arboreal legumes. MIRCEN Journal, 5:135 - 141.

Woomer, P.L., Karanja, and Kisamuli, S.M. (2010). Advancing Technical skills in Rhizobiology. N2Africa project. pp 1 59.

Zaman-Allah, M., Sifi, B., L'Taief, B., El-Aouni, M.H. and Drevon, J.J. (2007). Rhizobial Inoculation and $\mathrm{P}$ utilization response in common bean (Phaseolus vulgaris) under greenhouse and field conditions. Experimental Agriculture, 43: 67 - 77. 